\title{
Personal recovery and depression, taking existential and social aspects into account: A struggle with institutional structures, loneliness and identity
}

International Journal of Social Psychiatry $1-8$

(C) The Author(s) 2020

Article reuse guidelines: sagepub.com/journals-permissions DOI: I0.II77/00207640209388 I2 journals.sagepub.com/home/isp (SAGE

\author{
Janne Brammer Damsgaard ',2 iD, Camilla Lyhne Overgaard' \\ and Regner Birkelund ${ }^{3,4}$
}

\begin{abstract}
Background: Although depression is one of the most studied mental illness phenomena, the studies attempt to understand depression as different phases, turning points and transitions, but depression has an existential and social resonance. There is progress to be made in seeking to understand how people experience, cope and process, living with depression. There is a need of supplementary and alternative approaches that goes beyond medicine and traditional treatment of psychiatric disabilities.

Aim: The aim of this study was to explore perceptions and challenging issues related to living with depression, allowing the researchers to get a deeper understanding of existential and social aspects.

Method: A phenomenological-hermeneutic study design was applied, based on the French philosopher Paul Ricoeur's theory of interpretation. Data were collected through observations and semi-structured interviews.

Findings: Several of the interviewees were lonely at home as well as at the hospital. This caused experiences of sheer isolation with feelings of sadness enhancing desperation concerning what to do with themselves. This could even cause physical feelings of pain. In different ways, the interviewees expressed how being with other people filled their lives with relationships and closeness. Health care professionals were focused on applying structure into the users' everyday life, shadowing the person's individuality, strengths and resources. The prioritizations between users and healthcare professionals were not always in concordance. The interviewees experienced recurrent situations where their authority and individuality were ignored or felt non-existent.

Conclusion: Existential and social aspects are vital in regard to understanding people living with depression. However, personal recovery can be diminished by controlling structures and lack of a caring guidance, creating feelings of stigmatization missing out on autonomy, causing inner doubts. A recommendation is that we challenge institutional structures and accelerate education developing the healthcare professionals' empathic competences and ability to make wise judgments, empowering the users' autonomy.
\end{abstract}

\section{Keywords}

Personal recovery, depression, existential, structure, loneliness, individuality

\section{Background}

The World Health Organization (WHO) estimates that depression will constitute the greatest international disease burden in 2030, and nations around the world fear that we are facing a loneliness epidemic (Holt-Lunstad, 2018; WHO, 2004). This alarming fact is a wake-up call to further address this global challenge trying to understand loneliness and life with depression.

There is a vast body of existing research on depression focusing on observable and quantifiable measures, including extensive research on the causes and treatment of depression. Regarding the origin of depression, it is generally agreed that the disorder is caused by biological, psychological and social factors (Passer \& Smith, 2008).
Significant progress has been made in terms of understanding the biological bases of the depressed (Gilbert, 2016). Genetics and heredity, negative cognitive schemas,

\footnotetext{
'Psychiatric Research Unit West Herning, Regional Hospital West Jutland, Central Denmark Region, Herning, Denmark 2Department of Public Health, Aarhus University, Aarhus, Denmark ${ }^{3}$ University Hospital of Southern Denmark, Vejle, Denmark ${ }^{4}$ Department of Regional Health Research, University of Southern Denmark, Odense, Denmark

Corresponding author:

Janne Brammer Damsgaard, Psychiatric Research Unit West Herning, Regional Hospital West Jutland, Central Denmark Region, 7400 Herning, Denmark.

Email: jannedamsgaard@webspeed.dk
} 
early relational loss experiences, stressful life situations, lack of social support, stress and belonging to various social minority groups have all been identified as possible causes of depression (Hersen et al., 2007).

Qualitative studies have shed light on how depression is experienced. According to the findings of these studies, people facing depression endure considerable discomfort in living with the tensions of thought (Crona et al., 2017). They also feel a loss of dignity (Danielson \& Rosberg, 2015), intense sadness and yearning for joy in life (Crona et al., 2017) as well as a false and fading self that causes them to hide, isolate themselves and fear openness (Ahlström et al., 1997; Danielson \& Rosberg, 2015; Ridge \& Ziebland, 2006). Several studies show that depression is experienced as a lonely suffering, a separateness from a world that calls for a deep longing for belonging and a struggle to find meaning - depression has existential resonance (Bygstad-Landro \& Giske, 2017).

Although depression is one of the most studied mental illness phenomena (Gilbert, 2016), the studies attempt to understand depression as different phases, turning points and transitions (Danielson \& Rosberg, 2015; Karp, 1994; Ridge \& Ziebland, 2006). Only a few studies have allowed the afflicted persons' voices to be heard. There is therefore still progress to be made in seeking to recognize and understand how people experience, cope and process, living with depression. There is a need of supplementary and alternative approaches that go beyond traditional understanding of recovery and treatment of psychiatric disabilities striving to meet the individuals' existential and social needs (Forsberg et al., 2010; Wästberg et al., 2018).

The term 'recovery' is used based on different understandings and can roughly be seen from three angles clinical recovery, social recovery and personal recovery (Borg et al., 2013). Within a clinical understanding, recovery is seen as an effect of a treatment which can be measured. Social recovery can be seen as a (social) process which focuses on environmental, social and material conditions which can be inhibiting or conducive toward a more meaningful life (Borg et al., 2013).

However, an understanding of recovery as a personal and subjective experience has emerged within mental health systems (Slade et al., 2014). Within this understanding, the users' personal perspective and history is fundamental and seen to be something quite different from the results of a professional interaction. Here, recovery is not a performance or output but can be seen as a personal 'journey' which can be supported, but not controlled by professionals.

A growing amount of research argues that implementing recovery-oriented practice should be person-centered and focus on helping individuals live a meaningful life, in contrast to setting goals that are largely dictated by professionals (Davidson, 2016; Karlsson \& Borg, 2017; Slade et al., 2014).
But according to Slade et al., shifting to a practice that is built on equal partnership, hope-promoting and facilitating self-determination requires a transformation of services, practices and the paradigm within which they are delivered (Slade et al., 2014). Therefore, this meaning of recovery underpins mental health policy in many countries. Developing on this type of recovery will involve transformation within mental health systems, and human systems do not easily transform. In an article 'Uses and abuses of recovery', Slade et al. identify three scientific challenges, that is, broadening cultural understandings of recovery, implementing organizational transformation and promoting citizenship (Slade et al., 2014). The perspective has been defined as 'a deeply personal, unique process of changing one's attitudes, values, feelings, goals, skills, and/or roles' and 'a way of living a satisfying, hopeful, and contributing life even within the limitations caused by illness' (Anthony, 1993). Within this area, there is a gap in research whereas from within this angle, this study understands recovery and wants to contribute to clinical practice with new knowledge.

\section{Aim}

The aim of this study was to explore perceptions and challenging issues related to living with depression, allowing the researchers to get a deeper understanding of existential and social aspects.

\section{Methods}

\section{Design}

Within a phenomenological-hermeneutic approach, a qualitative design was chosen. The study involved semistructured interviews and applied Paul Ricoeur's phenomenological-hermeneutic theory of interpretation in processing the collected data (Ricoeur, 1979).

\section{Participants and data collection}

Three women and two men between the ages of 27 and 60 were interviewed - see Table 1. Taking in consideration that some of the users could be in an acute state of depressive suffering, we asked the nurse in charge who it was important not to disturb with the question of an interview. Having excluded these people, we asked the first four users listed on a flowchart. Moreover, taking into consideration that the participants were vulnerable, we spent some time at the hospital ward from which we recruited. This was to get acquainted with the setting and routines trying to find the best possible time where it would be appropriate to ask the users if they would be interested in participating in an interview. All people asked agreed to participate, and expressed contentment in getting the 
Table I. Data participants.

\begin{tabular}{lllll}
\hline Participant & Age & Gender & Level of depression & Other diagnosis \\
\hline A & 27 & $\sigma^{\pi}$ & Mild to moderate & Schizophrenic \\
B & 60 & $\sigma^{n}$ & Moderate severe to severe & None described \\
C & 44 & $\wp$ & Moderate severe to severe & Borderline; bipolar affective mental disorder \\
D & 56 & $\wp$ & Moderate severe to severe & Bipolar affective mental disorder \\
E & 29 & $\wp$ & Moderate severe to severe & Bipolar affective mental disorder \\
\hline
\end{tabular}

Table 2. Guide with prepared open questions.

Please, tell me about your everyday life.

Can you elaborate on what you just described?

Can you tell me how you experienced the depression?

Can you elaborate on what you described here?

Can you describe how you experienced being hospitalized?

Can you elaborate on that?

Beside medicine - what did you experience as healing for you?

Can you describe what it felt like?

Is there something that you would like to add or comment on?

opportunity to talk about their personal experiences. The fifth user asked was discharged but connected with an outpatient co-operation between municipality and the regional psychiatry and had expressed interest in participating. Four interviews took place at the hospital ward and one (the interview with the person attending the outpatient co-operation) at a library. In regard to the users admitted at the hospital, the interview setting was chosen so that it would interfere as little as possible with other activities. The data generation was performed in co-operation by two of the authors from May to June 2019. The authors asked questions in turn and when it felt appropriate to do so, based on a respectful and sensitive attitude with focus on the participant and attention on leaving room for the other interviewer.

A semi-structured interview guide with open questions was used (Kvale \& Brinkmann, 2015) see Table 2. To achieve openness in the interviews, the participants were asked broad and open questions through which they were asked to describe and reflect on how they had experienced living with depression. The interviews commenced with questions such as 'Can you tell me how you experienced the depression?'; 'Can you describe how you experienced being hospitalized'; and 'Beside medicine - what did you experience as healing for you?' During the interviews, the participants' reflections directed the interviewers, but we specifically strived to focus on existential and social concerns in relation to mental health. These perspectives were based on clinical experience and a vast amount of studies suggesting more research within the field of users' perspectives on living with depression, hospitalization and personal recovery (Borg et al., 2013; Bygstad-Landro \& Giske, 2017; Madsen, 2018; Mezzina et al., 2006; Slade et al., 2014). Within this field, the interviewers wanted the interviews to be broad and open.

The interviews lasted between 45 and 60 minutes and were subsequently transcribed verbatim.

\section{Ethical considerations}

Qualitative nursing research among vulnerable users may lead to ethical dilemmas and requires the researcher to be an ethical, knowledgeable and sensitive human being (Angel \& Vatne, 2017; Benner et al., 2009; Brinkmann \& Kvale, 2005). Therefore, the researcher must be guided by ethical principles to protect study participants and ensure that the study is based on justice, beneficence and respect for human dignity. In addition, the researcher must understand and conduct procedures such as informed consent and confidentiality (Polit \& Beck, 2017).

All patients were informed both verbally and in writing about the purpose of the project. They were assured that participation was voluntary, that they would be able to withdraw from the project at any time, and that all data would be made anonymous (Declaration of Helsinki, 1964).

According to Danish law, approval from the Regional Committee for Medical Research was not required because of the non-biomedical character of the study. Approval from the Danish Data Protection Agency was obtained (journal number: 1-16-02-30-19) and their requirements for safe data storage were adhered to.

\section{Data analysis and interpretation}

According to Ricoeur, the aim of a hermeneutic interpretation of a text is to understand the world opened in front of the text (Ricoeur, 1976). Thus, interpretation is to move from what the text says to what the text speaks about (Ricoeur, 1976). Striving to interpret, understand and create meaning and thereby achieve deeper insight and new knowledge, the users' experiences were therefore explored through descriptions gained in the interviews, where the interpretation had already begun.

Inspired by Ricoeur's theory of interpretation, we conducted a three-level interpretation process to reveal the meanings of the users' experiences (Ricoeur, 1976). The process included the phases such as naïve reading, 
Table 3. Example of the analysis process - from quote to theme.

\begin{tabular}{|c|c|c|}
\hline $\begin{array}{l}\text { Meanings units/quotations } \\
\text { 'What is said' }\end{array}$ & $\begin{array}{l}\text { Units of significance } \\
\text { 'What the text speaks about' }\end{array}$ & Sub-themes \\
\hline $\begin{array}{l}\text { ' } . \text {. then comes the loneliness, the hopelessness, } \\
\text { the frustration - it is such a heavy burden - and } \\
\text { then the anxiety appears - it hurts so much - it's } \\
\text { like muscles with cramps run through with a } \\
\text { spear'. }\end{array}$ & $\begin{array}{l}\text { The text speaks about a need for relationships, closeness } \\
\text { and caring in the 'journey' toward personal recovery. It } \\
\text { is not just about receiving, but also about the feeling of } \\
\text { giving. The feeling of belonging, and being recognized, } \\
\text { takes part in reducing loneliness. The text speaks about } \\
\text { thoughts and incidents in regard to living everyday life } \\
\text { experiencing recurrent situations where integrity as an } \\
\text { individual is non-existent or ignored. }\end{array}$ & Being alone \\
\hline $\begin{array}{l}\text { '. . instead of saying to people that they have a } \\
\text { diagnosis, just say - "you're different from some." } \\
\text { Clearly, I do not see myself as a diagnosis - not } \\
\text { at all - I see myself as different to other people - } \\
\text { and it is sometimes important to differ from what } \\
\text { people are the most ...' }\end{array}$ & $\begin{array}{l}\text { The text speaks about being an individual on one's own } \\
\text { terms. The text indicates that users can experience } \\
\text { stigmatization feeling equivalent to their diagnosis. This } \\
\text { reduces the individuals' right to diversity and self- } \\
\text { determination. }\end{array}$ & $\begin{array}{l}\text { Being an } \\
\text { individual }\end{array}$ \\
\hline
\end{tabular}

Table 4. Themes and subthemes.

\begin{tabular}{ll}
\hline Themes & Subthemes \\
\hline Personal & - Being alone \\
recovery & - Being and individual \\
In search of & - Contemplation creates inner calmness \\
meaning & - A search for hope \\
Culture within & - Defined by use of biomedical terms \\
psychiatry & - Different understandings of mental health \\
\hline
\end{tabular}

structural analysis and comprehensive understanding. According to Ricoeur, this method benefits from the dialectical movement between explanation and understanding and provides an understanding of what the text as a whole addresses (Missel \& Birkelund, 2019; Ricoeur, 1976).

In the naïve reading, the text was read several times and with as open a mind as possible to achieve an initial understanding of what it was all about. Ricoeur emphasizes that this phase is important but must be validated by subsequent structural analysis.

In the structural analysis, we structured and explained the text by units of meaning (what is said) and units of significance (what the text speaks about) - see Table 3. The analysis was characterized by a dialectical reflection between explanation and interpretation (Ricoeur, 1976). This allowed us to achieve a deeper understanding of the text, creating themes and subthemes - see Table 4 .

The last level of interpretation was conducted as a comprehensive understanding that entailed revising, broadening and deepening the awareness through critical reflection (Ricoeur, 1976). The themes derived from the texts in the structural analysis became the basis of the comprehensive understanding (Ricoeur, 1976). Relevant theoretical perspectives and existing research were included to achieve new insight, thus creating new knowledge about the citizens' experiences of what was meaningful to mental health.

\section{Findings}

\section{Naiive reading}

The naïve reading of the texts showed that the interviewees experienced fellow humans as being influencing factors to their personal recovery. The positive or negative impact from society, healthcare professionals communities or family/ friends was vital to the way they considered themselves, and whether life was experienced as meaningful or not.

\section{Structural analysis}

Being alone. Several of the interviewees explained about feelings of being lonely at home as well as at the hospital. This caused experiences of sheer isolation with feelings of sadness, enhancing desperation concerning what to do with themselves. This could even cause physical feelings of pain. A woman explained it like this:

. . . then comes the loneliness, the hopelessness, the frustration - it is such a heavy burden - and then the anxiety appears - it hurts so much - it's like muscles with cramps run through with a spear.

Such extreme loneliness experiences instilled feelings of inner doubts. This affected reflections and belief in personal identity - in who they were as a human being. However, in different ways, the interviewees expressed how being with other people filled their life with relationships, closeness and caring - contributing to form their identity. A woman described it like this:

It is more about recognition. It is so pleasant if someone asks where they can buy a purse like mine or comments on something that I have done well.

Being integrated in a group relating to other people is not just about one-way receiving; the feeling of contributing 
and being somebody for others is experienced as valuable and important to mental health. A woman stated it this way:

... then I could still feel that I did something for another person. I love listening to the life story of the elderly. It is like reading a book, drinking coffee together or going for a walk in the park.

However, several of the interviewees pointed out that the overwhelming feelings of loneliness are an aspect which they struggle with in any given setting - that is to say, being at home, being in a hospital or even joining communitybased activities. A woman explained by referring to an experience in a local community center:

Well, we are often left alone for 3 or 4 hours. Once in a while they (healthcare professionals) pop in just to see that we are there and then they go and get their coffee returning to the office.

From many angles, the interviewees described thoughts and incidents concerning their presence as an individual. Living their everyday life, they experienced recurrent situations where their authority and individuality were ignored or felt non-existent. Such experiences were expressed as demeaning to them.

Being an individual. Interacting with the healthcare system the users struggled with being affiliated with a diagnosis. This contributed to difficulties with getting to terms with who they were as an individual. It was difficult for the people to step out of the role of 'being a patient'. A young man stated it this way:

... instead of saying to people that they have a diagnosis just say - 'you're different from some'. Clearly, I do not see myself as a diagnosis - not at all - I see myself as different to other people - and it is sometimes important to differ from what people are the most...

Listening to the interviewees, it appears that the healthcare professionals were very focused on applying structure to the users' everyday life, shadowing individuality, strengths and resources. The prioritizations between patients and healthcare professionals were not always in concordance.

A woman experienced the following with her support worker:

. . . and she said that I couldn't prioritize my time - 'we must make a list of prioritizations', she said. I got really mad, because she didn't let me speak out . . .

Such experiences were highlighted by several of the interviewees and made them feel that they were 'just one of many', being neglected as a human being. This made them feel that their authority and right to make decisions were not taken in consideration. Instead, forms with agreements became controlling - and to some extent, once they were agreed on - unchangeable. This was experienced as a standardizing and stigmatizing approach missing out on the individual person.

Within this perspective, several of the interviewees talked about how, for example, taking a walk, listening to the birds and getting out in the fresh air could be an important activity and counterbalance to ordinary surroundings and impressions.

... I can wander about feeling as if the nature and I are one unity - this is a very healing experience.

However, it seems that, for example, the healing power of nature is not a particularly incorporated part of the healthcare professionals' understanding of what contributes to the users' recovery. A man explained it this way:

It would be very nice to go for a long walk with someone from the hospital - maybe it could be a student. Well, to walk with someone, not being alone. However, there are never enough staff - it always ends up with just a short walk - but you can't do anything about it.

Such experiences underline that the healthcare professionals' understanding and judgment concerning the importance of activities is crucial. Thus, a caring guidance into what, for example, nature can infuse is vital in regard to the recovery process.

A woman explained this in the following, nuanced way:

. . . no, I feel that they are letting me down - they are pushing me out . . . because in the beginning I was instructed to go out. It made me go to pieces - I was very afraid to go out alone - what would I do and things like that.

Such experiences indicate that the way healing initiatives are presented, articulated, handled and understood by the healthcare professionals is important - adding to personal recovery, if well integrated in the treatment and everyday life.

\section{Comprehensive understanding}

\section{Being alone}

When reflecting, the interviewees shared stories holding experiences where sense of belonging was a focal point. Loneliness, isolation and experiencing being seen as equivalent to their diagnosis could cause feelings of doubt in who they were as a person. Being integrated in a group was important and contributing to recovery - however, many interviewees described this as a constant struggle being met by experiences of loneliness in many settings. 
Nurse theorist Jean Watson argues that every human being has the need to be accepted and to belong, establishing and maintaining one's identity. Individual distinction comes from the way a person conducts his or her own life in relation to other people and this need is, according to Watson, centered in sharing, balancing individual and group dynamics finding self in others and vice versa (Watson, 2008). In this light, the interviewees' lack of belief in themselves, struggling with who they are as a person, is understandable. The constellation of 'I-We', 'MeUs' constitutes a dialectical dynamic that helps define the interactive process of achieving self-identity (Watson, 2008). We learn about 'oneself' and 'others' from the experiences of our physical, social, behavioral and emotional day-to-day environment and relationships. Affiliation allowing feedback from others helps us shape our thoughts and feelings, which helps us to identify and reduce anxiety and feelings of isolation.

It is therefore understandable that the interviewees' recurrent loneliness experiences instilled feelings of desperation and inner doubts prompting who they were as a human being. For the healthcare professionals this is crucial knowledge to consider when interacting with the patients.

\section{Being an individual}

Through the stories, it emerged that systems and structures in some cases felt controlling and hard to re-negotiate if once agreed on. This was experienced as a standardizing and stigmatizing approach missing out on the individual person. The way initiatives were valued, handled and articulated by the healthcare professionals was important adding to recovery, if integrated in a caring way.

Sociologist Axel Honneth writes about the importance of the human experience of being recognized as an individual and the opposite - lack of recognition. In the article Invisibility: On the Epistemology of 'Recognition' (Honneth, 2001), he connects the phenomenon of 'recognition' closely to visibility, while 'violation' is connected to invisibility, where the other person may be seen or registered, but is not assigned authority (Juul, 2011), for example, not recognized as an equal and trustworthy person.

Honneth is concerned with how a human being can experience not being recognized, but rather feel 'overlooked' and violated in social contexts (Honneth, 2001, 2003). This is perceived as disappearing as a person and this has nothing to do with physical non-presence, but the non-existence of social significance. In our everyday use of language, there are inherent patterns of approval or disapproval, so when the patients feel neglected, being affiliated with a diagnosis or 'instructed' without caring guidance, they are 'injured' in regard to a positive understanding of themselves.

According to Honneth, every human being is dependent on a positive self-image which is supported by others. The experience of being disrespected carries with it the danger of an injury that can bring the identity of the person as a whole to the point of collapse (Honneth, 1995). When participants found themselves in social contexts where their autonomy was not recognized, it caused them to feel that they were not being recognized as human beings. The feeling of being ignored leads to anger, resistance and feelings of stigmatization - disconnecting the person, hindering recovery.

\section{Discussion}

\section{Discussion of research}

In this study, the participants described how loneliness and isolation could affect their everyday life creating doubt in who they were as an individual. Being somebody for others created feelings of recognition adding to their personal recovery. Moreover, empowering experiences of belonging were described as crucial but also as experiences that were hard to attain and could be challenged in many social settings, for example, when dealing with objectifying effects of a diagnosis, having to subject to specific schemas and structures or being overlooked in a local community center.

A review by Salzmann-Erikson shows that recovery retaining meaning in life is an inner process that takes place within the person and is about self-accepting and identifying oneself based on the existing circumstances (Salzmann-Erikson, 2013). The inner process of recovery is initiated by a sparking of hope and faith for a future. Recovery is about 'accepting' to be able to move forward in the process.

In addition, and in line with our findings, acceptance, to Salzmann-Erikson, is also understood from another perspective, that is, the importance of being accepted by others in the near surroundings (Salzmann-Erikson, 2013). It is important to be in contact with the surrounding world since isolation could lead to depression, loneliness and doubt in who we are. This provides a structure on a daily basis. In line with our study, this is also an important aspect to consider by professionals surrounding the users.

Within this perspective, Mezzina et al. advocate for supportive non-controlling arenas where people can have the ability to be themselves and not be reduced and stigmatized to symptoms and to diseases (Mezzina et al., 2006). This supports our findings that having to subject to certain schemas and structures or getting a diagnosis can create feelings of being different and objectified, ignoring individuality and authority. This is important knowledge to integrate in the caring and treatment of people living with depression.

However, several studies find that being diagnosed can be a twofold experience (Brinkmann, 2016; Damsgaard et al., 2016). A study by Probst raises questions about the assumption that diagnostic labels necessarily bring shame and loss of self-efficacy. Probst finds that diagnostication 
can bring validation. Being 'named' was to be welcomed into one's tribe (Probst, 2015). For others, being diagnosed meant reduction and mistranslation. Along with our findings, it is therefore crucial that healthcare professionals must remain open to discovering how each person finds the healing process to be meaningful.

To sum up, there emerges both an existential and a contextual or social dimension understanding persons living with depression. That is, struggling with controlling environments, diminishing autonomy, creating feelings of resistance, being ignored, and at the same time feelings of social isolation and loneliness. During a mental health crisis, this can be difficult to cope with, creating dilemmas when interacting with the healthcare system.

\section{Methodological considerations}

This study was based on the interviews of five users which is a very small number of participants. But since the aim of qualitative studies is to gain a deeper insight into the lifeworld of users it is irrelevant to discuss the number of participants (Polit et al., 2001). It is, however, relevant whether the selected participants can redeem the problem under study (Flyvbjerg, 2006, 2020). The participants in our study were chosen because of their affliction and because they were undergoing treatment. Retrospectively, we assessed that the participants were well suited to enter the study, as their stories portrayed that they had reflected on and thought a great deal about living life with a depression. We conclude that the themes and subthemes that materialized from the interviews and the interpretations that evolved will be of inspiration to healthcare professionals' further educational journey securitizing the participants' lifeworld. However, it was not our intention to generate generalizable knowledge using the phenomenological-hermeneutical method to discover what life with depression is like, only what life may be like. Neither was it our intention to test the evidence of the applied theories, but to discuss the themes that arose from the participants' stories from several theoretical perspectives, being well aware that the course of each user will always be unique.

\section{Conclusion and implications for practice}

This study shows that existential and social aspects are vital in regard to understanding people living with depression. Personal recovery can be diminished by controlling structures and lack of a caring guidance, creating feelings of stigmatization missing out on autonomy, causing inner doubts and resistance.

Social relationships and an acknowledging environment can enhance a feeling of belonging, recognition and the journey toward recovery. It is argued that a stronger focus on the importance of being socially included and thereby recognized is acquired by the healthcare professionals.

Within this perspective, there is a need for awareness of existential and social aspects. Such an awareness entails that healthcare professionals develop competences - are being educated - in being able to make good use of judgment, ingenuity and kindness by opening their eyes to people and their range of problems. However, education does not consist of accumulation of knowledge and ways of explanation through diagrams, structures and theories. We do not become competent healthcare professionals by being able to reproduce theoretical or philosophical ideas. These are merely perspectives by means of which we can seek to go beyond what we take for granted, or what we assume to know, thus enabling us to take a new direction that until now may have been hidden to us. 'True' cognition does not consist of words, phrases or theories. It lies latent in our souls and waits for being set free. True cognition is in other words of an existential character. Concepts are only meaningful if we have prerequisite qualifications based on experience to understand what they imply. Therefore, the experience-based knowledge is always richer on information than the description of it would be. The more abstract the concepts and theories are, the less they speak to us and relate to experiences based on our concrete lifeworld context; hence clinical practice can broaden its perspective by listening to the users, developing the professionals' contemplation and personal insight in regard to empathic competencies and ability to make wise judgments, empowering the users' autonomy - acting upon the experiences of each individual, and supporting their personal recovery.

\section{Conflict of interest}

The author(s) declared no potential conflicts of interest with respect to the research, authorship and/or publication of this article.

\section{Funding}

The author(s) received no financial support for the research, authorship and/or publication of this article.

\section{ORCID iD}

Janne Brammer Damsgaard (iD https://orcid.org/0000-0003-1238 $-2344$

\section{References}

Ahlström, B. H., Skärsäter, I., \& Danielson, E. (1997). Living with major depression: Experiences from families' perspectives. Scandinavian Journal of Caring Sciences, 23(2), 309-316.

Angel, S., \& Vatne, S. (2017). Vulnerability among patients and nurses and the mutual vulnerability in the patient-nurse relationship. Journal of Clinical Nursing, 26, 1428-1437. 
Anthony, W. A. (1993). Recovery from mental illness: The guiding vision of the mental health system in the 1990s. Psychosocial Rehabilitation Journal, 16, 11-23.

Benner, P., Tanner, C. A., \& Chesla, C. A. (2009). Expertise in nursing practice: Caring, clinical judgment and ethics (2nd ed.). Springer.

Borg, M., Karlsson, B., \& Stenhammer, A. (2013). Recoveryorienterede praksisser. En systematisk vidensopsamling [Recovery oriented practice. A systematic gathering of knowledge] (Nationalt Kompetansesenter for Psykisk Helsearbeid NAPHA,4).https://psykosocialrehabilitering.dk/wp-content/ uploads/2016/03/Recoveryorienterede_praksisser.pdf

Brinkmann, S. (2016). Diagnostic cultures: A cultural approach to the pathologization of modern life. Routledge.

Brinkmann, S., \& Kvale, S. (2005). Confronting the ethics of qualitative research. Journal of Constructivist Psychology, 18(2), 157-181.

Bygstad-Landro, M., \& Giske, T. (2017). Risking existence: The experience and handling of depression. Journal of Clinical Nursing, 27, e514-e522.

Crona, L., Stenmarker, M., Öjehagen, A., Hallberg, U., \& Brådvik, L. (2017). Taking care of oneself by regaining control: A key to continue living four to five decades after a suicide attempt in severe depression. BMC Psychiatry, 17(1), Article 69.

Damsgaard, J., Jørgensen, L., Norlyk, A., \& Birkelund, R. (2016). Spinal fusion surgery: From relief to insecurity. International Journal of Orthopaedic and Trauma Nursing, $24,31-39$.

Danielson, L., \& Rosberg, S. (2015). Depression embodied: An ambiguous striving against fading. Scandinavian Journal of Caring Sciences, 29(3), 501-509.

Davidson, L. (2016). The recovery movement: Implications for mental health care and enabling people to participate fully in life. Health Affairs, 35(6), 1091-1097.

Declaration of Helsinki. (1964).

Flyvbjerg, B. (2006). Five misunderstandings about case-study research. Qualitative Inquiry, 12(2), 219-245.

Flyvbjerg, B. (2020). Fem misforståelser om casestudiet [Five misunderstandings about the case-study research]. In S. Brinkmann \& L. Tanggaard (Eds.), Kvalitative metoder. En grundbog (3rd ed., pp. 621-656). Hans Reitzels Forlag.

Forsberg, K. A., Björkman, T., Sandman, P. O., \& Sandlund, M. (2010). Influence of lifestyle intervention among persons with psychiatric disability: A cluster randomized controlled trial on symptoms: Quality of life and sense of coherence. Journal of Clinical Nursing, 19, 1519-1528.

Gilbert, P. (2016). Depression. The evolution of powerlessness. Routledge.

Hersen, M., Turner, S. M., \& Beidel, D. C. (2007). Adult psychopathology and diagnosis (5th ed.). John Wiley.

Holt-Lunstad, J. (2018). The potential public health relevance of social isolation and loneliness: Prevalence, Epidemiology, and risk factors. The Gerontological Society of America, 27, 127-130.

Honneth, A. (1995). The struggle for recognition. The moral grammar of social conflicts. The MIT Press.

Honneth, A. (2001). Recognition. I - Axel Honneth. Invisibility: On the epistemology of 'Recognition'. Proceedings of the Aristotelian Society, Supplementary Volumes, 75, 111-126.

Honneth, A. (2003). Usynlighed - om 'anerkendelsens' erkendelsesteori [Invisibility - about the epistemology of 'recognition].
In R. Willig (Ed.), Behovet for anerkendelse - en tekstsamling (1st ed., pp. 98-109). Hans Reitzels Forlag.

Juul, S. (2011). Solidaritet: anerkendelse, retfoerdighed og god dømmekraft. En kritisk analyse af barrierer for sammenhoengskraft $i$ velfoerdssamfundet [Solidarity: recognition, justice and good judgement. A critical analysis of cohesion barriers in the welfare system] (1st ed.). forfatteren og Hans Reitzels Forlag.

Karlsson, B., \& Borg, M. (2017). RECOVERY. Tradisjoner, fornyelser og praksiser [RECOVERY. Traditions, renewals and practises]. Gyldendal.

Karp, D. A. (1994). Living with depression: Illness and identity turning points. Qualitative Health Research, 4(1), 6-30.

Kvale, S., \& Brinkmann, S. (2015). Interview. Det kvalitative forskningsinterview som håndvark (3rd ed.). Hans Reitzel.

Madsen, A. K. W. (2018). Recovery orientation in clinical practice: How does it unfold in mental health inpatient settings? University of Copenhagen.

Mezzina, R., Borg, M., Marin, I., Sells, D., Topor, A., \& Davidson, L. (2006). From participation to ciitizenship: How to regain a role, a status, and a life in the process of recovery. American Journal of Psychiatric Rehabilitation, 9(1), 39-61.

Missel, M., \& Birkelund, R. (2019). Ricoeur's narrative philosophy: A source of inspiration in critical hermeneutic health research. Nursing Philosophy, 21, Article e12254. https:// doi.org/10.1111/nup.12254

Passer, M. W., \& Smith, R. E. (2008). Psychology. The science of mind and behaviour (4th ed.). McGraw-Hill.

Polit, D. F., \& Beck, C. T. (2017). Nursing research: Generating and assessing evidence for nursing practice. Lippincott Williams \& Wilkins.

Polit, D. F., Beck, C. T., \& Hungler, B. P. (2001). Essentials of nursing research. Methods, appraisal and utilization (5th ed.). Lippincott Williams \& Wilkins.

Probst, B. (2015). Queen of the owls: Metaphor and identity in psychiatric diagnosis. Social Work in Mental Health, 13, 235-251.

Ricoeur, P. (1976). Interpretation theory: Discourse and the surplus of meaning. Texas University Press.

Ricoeur, P. (1979). Fortolkningsteori [Theory of interpretation]. Vintens Forlag.

Ridge, D., \& Ziebland, S. (2006). The old me could never have done that: How people give meaning to recovery following depression. Qualitative Health Research, 16(8), 1038-1053.

Salzmann-Erikson, M. (2013). An integrative review of what contributes to personal recovery in psychiatric disabilities. Issues in Mental Health Nursing, 34, 185-191.

Slade, M., Amering, M., Farkas, M., Hamilton, B., O’Hagan, M., Panther, G., Perkins, R., Shepherd, G., Tse, S., \& Whitley, R. (2014). Uses and abuses of recovery: Implementing recovery-oriented practices in mental health systems. World Psychiatry, 13, 12-20.

Wästberg, B. A., Sandström, B., \& Gunnarsson, A. B. (2018). New way of working: Professionals' expectations and experiences of the Culture and Health Project for clients with psychiatric disabilities: A focus group study. International Journal of Mental Health Nursing, 27, 329-340.

Watson, J. (2008). Nursing: The philosophy and science of caring. University Press of Colorado.

World Health Organization. (2004). WHO global burden of disease. https://www.who.int/healthinfo/global_burden_disease/2004_ report_update/en/ 